\title{
De mica en mica s'omple la pica de Jaume Fuster: un intent de consolidar la novel·la negra i policíaca a Catalunya
}

\author{
Jaume Fuster's De mica en mica s'omple la pica \\ as an attempt to consolidate crime fiction in Catalonia
}

\author{
Magdalena Wegner \\ Uniwersytet im. Adama Mickiewicza w Poznaniu \\ magdalena.wegner@amu.edu.pl
}

\begin{abstract}
Discussing the Catalan crime fiction may appear as a challenging scientific task due to its lacking autochthonous tradition. The scholars exploring this issue have come to conclusion that, even though there were authors such as Rafael Tasis o Manuel de Pedrolo, whose contribution to this literary genre's solid foundations seems indubitable, Jaume Fuster is the writer responsible for its consolidation in the Catalan literary system in the 1970s. The aim of the present paper is to analyze Jaume Fuster's De mica en mica $s$ 'omple la pica in a specific historical context in order to present some of his foreign influences and inspirations. Specifically, it investigates whether the author remained indifferent to external literary products or whether he chose deliberately some of the archi-genre's elements in order to implement and consolidate crime fiction in Catalonia. For this purpose, we have applied some of the principles of Even-Zohar's Polysystem Theory. The results showed that De mica en mica s'omple la pica not only has played a major role in the consolidation of crime fiction but it also placed its author in one of the central positions in the Catalan literary polysystem. Moreover, Fuster tended to interact with different foreign traditions by using in his works modified crime fiction components based on the unique repertory conditioned by the geopolitical situation of Catalonia.
\end{abstract}

Keywords: Contemporary Catalan literature, Jaume Fuster, crime fiction, La Cua de Palla, polysystem theory 


\section{INTRODUCCIÓ}

Sembla que si un escriptor està condicionat pel seu moment històric concret, la seva obra també reflexionarà a l'entorn d'una problemàtica similar. Jaume Fuster (1945-1998) no n'era cap excepció. Sens dubte, la seva vida va estar marcada per les conseqüències de la Guerra Civil i la dictadura franquista, que van suposar una ruptura en tota la societat catalana dels seus paràmetres econòmics, ideològics i literaris. Malgrat els obstacles per fer-se adult en una Barcelona fosca, deficient a nivell institucional i amb un futur incert, Fuster va ser capaç de convertir-se en un dels escriptors catalans més importants de la segona meitat del segle XX i contribuir no només a l'exitosa introducció de la literatura de gènere al sistema literari, sinó també a atorgar-li un matís de versemblança necessària perquè el públic lector comencés a llegir de forma més freqüent novel·les de lladres i serenos en llengua catalana.

Rastrejant la seva polifacètica trajectòria professional, destaquen tasques desenvolupades com a escriptor, traductor, guionista, activista cultural i polític, articulista o crític literari; no obstant això, és de cabdal importància subratllar també l'entusiasme de Fuster pels productes de la cultura popular, com pel·lícules, novel·les de gènere o tebeos, que també van exercir un paper rellevant en el procés de formació generacional d'altres autors. Com afirma Martín Escribà (2020, p. 67-68), "Fuster, entre d'altres, responia a una consideració de tipus generacional i social fonamentada en la data de naixement de la majoria d'aquells autors que començaren a produir als anys setanta, triant l'opció per l'escriptura en llengua catalana". El moment de les primeres publicacions d'aquests escriptors va coincidir amb canvis importants relacionats amb l'arribada de la democràcia, que suposaven també diversos condicionants favorables a l'ús de català com a llengua literària amb un públic lector creixent. Clarament, aquest pas cap a la "normalització" del sistema literari català estava vinculada amb un cert aspecte ideològic, però hi havia també altres elements que van contribuir-hi, entre els quals podríem esmentar tota la infraestructura editorial, amb uns mitjans de comunicació cada vegada més forts i el reconeixement del català com a llengua vehicular del sistema educatiu. Comparant aquestes circumstàncies amb la situació de la postguerra quan Rafael Tasis ${ }^{1}$ o Manuel de Pedrolo ${ }^{2}$ publicaven les seves primeres

${ }^{1}$ La seva trilogia, formada per La Bíblia valenciana (1955), És hora de plegar (1956) i Un crim al Paralelo (1960), va suposar la primera incursió en el gènere policíac a la Catalunya de postguerra. Parallelament, va participar activament en el procés de reinstauració del gènere com a crític literari i traductor, formant part de la col·lecció La Cua de Palla. Per saber-ne més, vegeu l'estudi de Martín Escribà Rafael Tasis, novel-lista policíac (2015).

${ }^{2}$ L'aportació de Pedrolo al procés d'importació dels models nord-americans del gènere negre és inqüestionable. L'autor assenyalava la necessitat de publicar els gèneres populars per arribar a allò que es descriuria com "la normalització lingüística" (Pedrolo, 1972, p. 44), per tant, no és d'estranyar que dirigís la col·lecció La Cua de Palla (1963-1970) d’Edicions 62, que va ser el primer projecte d'aquest 
obres, sembla que aquells intents foren massa prematurs, però, al mateix temps, summament rellevants per al desenvolupament del gènere negre i policíac en català de cara a les futures generacions ${ }^{3}$.

\section{DE MICA EN MICA S'OMPLE LA PICA EN EL CIRCUIT LITERARI CATALÀ}

La primera novel·la de Fuster va ser Abans del foc (1971). Tanmateix, ni la crítica ni el públic lector van acollir-la positivament i, per tant, s'ha tendit a perfilar la seva carrera literària a partir de la segona novel·la publicada, és a dir, De mica en mica s'omple la pica (1972), que més endavant es convertiria en un dels bestsellers catalans. Tal com explica Martín Escribà (2018, p. 47-51), Fuster va escriure-la pensant en la col·lecció La Cua de Palla. Malauradament, no va poder acomplir aquest objectiu, perquè la censura va demorar notablement el procés de la seva publicació i l'enllestiment del text va coincidir amb el tancament de la col·lecció l'any 1970. Finalment, la novel·la va aparèixer l'any 1972 a la col·lecció El Balancí, també d'Edicions 62 . Com que Fuster encara era un escriptor jove sense visibilitat en el món literari, els seus editors van demanar-li un pròleg de Manuel de Pedrolo. A cap dels dos escriptors no els atreia la idea d'escriure aquesta mena de paratextos, però entenien molt bé l'organització de la infraestructura editorial. D'aquesta manera, un autor consagrat com ja era Pedrolo indicava el seu hereu, un hereu que seria capaç de consolidar el gènere a Catalunya, aprofitant els fonaments llegats per tot l'equip de La Cua de Palla ${ }^{4}$.

tipus en llengua catalana. Es tractava d'una compilació de traduccions de novel·les policíaques i negres d'autors consagrats perquè el públic lector pogués conèixer-los en la seva llengua pròpia i, més endavant, pogués convertir-se eventualment en escriptor d'aquest tipus de literatura. Al cap de set anys d'existència, la col·lecció havia publicat 71 títols, la immensa majoria dels quals formaven part d'una selecció d'autors forans, és a dir 69 novel·les. Sols dues eren obra de Manuel de Pedrolo, en concret Joc brut (1965) i Mossegar-se la cua (1968). En aquesta selecció d'obres predominaven els escriptors anglosaxons (46), per bé que més endavant es publicarien autors francòfons (21) i les dues últimes novel·les són de Friedrich Dürrenmatt, traduïdes de l'alemany. Per saber-ne més, vegeu els treballs Pedrolo contra els límits (2018), d'Arbonès i Montull, i La cua de palla: retrat en groc i negre (2011), de Canal i Artigas i Martín Escribà.

${ }^{3}$ Andreu Martín va participar en Les veus del crim de Villalonga (2013, p. 204), i hi afirmava: “Amb els llibres de La Cua vaig començar a llegir novel·la policíaca. I vaig quedar fascinat. A la mateixa època vaig llegir De mica en mica s'omple la pica, que em va ensenyar que es podia explicar una història criminal ambientada aquí...".

${ }^{4}$ El mateix escriptor va explicar l'origen d'aquesta novel·la en una entrevista de l'abril de 1996 feta per Rosa Pagès (2013) que va restar inèdita fins fa uns anys, en la qual també va deixar dit el següent: "El mateix Pedrolo va esbombar que era el seu hereu en aquest sentit, com a novel·lista de gènere. Des d'aleshores he publicat algunes novel·les més, i sobretot he tingut la satisfacció de veure com aquest camí que jo emprenia el continuaven altres membres de la generació, superant-lo fins i tot. I alguna cosa 
Un altre factor imprescindible en el procés de legitimació de l'obra de Fuster va ser la seva presència en les revistes culturals catalanes, com Serra d'Or, i les crítiques positives de la novel'la per part d'autors importants i ressenyadors professionals. Caldria subratllar que abans de la seva primera incursió en la novel-lística, Fuster va escriure Breu història del teatre català (1967), un assaig publicat per Bruguera, que li va permetre introduir-se al món de l'art dramàtic. D'aquesta manera, va poder entaular relacions amb diversos representants del panorama coetani de la literatura catalana, com ara Maria Aurèlia Capmany, que també publicava els seus articles a Serra d'Or i estava estretament vinculada a la creació teatral. Aquí destaca el paper que exercien els mitjans de comunicació com a component de la institució, que segons Even-Zohar (1990, p. 37-38), es defineix com el conjunt de factors implicats a l'hora de controlar la cultura. Aquest agent no solament determina quins models o productes seran protegits i conservats a llarg termini en una comunitat concreta, sinó també és capaç d'assistir en el procés de creació de nous patrons i la seva consegüent incorporació al sistema. Com exposa Even-Zohar (1990, p. 37-38), existeixen diferents entitats que lluiten en paral·lel per les posicions més importants dins d'aquest conjunt $i$, normalment, no es pot parlar d'homogeneïtat a nivell institucional. No obstant això, sembla que en el cas de la consolidació del gènere negre i policíac amb l'obra de Jaume Fuster aquests agents van collaborar profitosament, atès que els seus objectius van coincidir amb uns esdeveniments polítics i socials favorables. Tals condicions van permetre que les editorials poguessin optar pels escriptors joves i les seves novel·les, cosa que significava la creació d'una continuïtat generacional en el panorama literari i l'acompliment (parcial) d'expectatives d'un determinat sector del públic lector català. En aquell temps, les editorials podien comptar amb publicitat en els mitjans de comunicació, també un component de l'esmentada institució, a fi de generar més vendes de certs títols. Observant la posició del gènere negre i policíac en els altres sistemes literaris, especialment els dominants, totes les entitats reconeixien el potencial d'aquesta modalitat narrativa com a producte que, gràcies a la seva forma i a elements constitutius atraients, podia convertir-se en un vehicle rellevant de denúncia social i, al mateix temps, podia generar ingressos per a futures publicacions.

En aquest cas, Edicions 62 va promocionar les dues novel-les de Fuster esmentades anteriorment amb Cròniques de la molt anomenada ciutat de Montcarrà (1972), de la mallorquina Maria-Antònia Oliver ${ }^{5}$. Com s'ha dit més amunt, fins aquell moment Fuster no comptava amb cap premi literari que augmentés les xifres de venda,

m’he d'atribuir, perquè com a mínim sóc el primer que ho va fer, i qui és el primer, si més no estableix els paràmetres o enceta camins". A més, per commemorar l'aportació de Pedrolo al gènere negre i policíac i el centenari del seu naixement, es va organitzar una taula rodona dins del festival BCNegra 2018 titulada "Tots som hereus de Manuel de Pedrolo".

${ }^{5}$ Vegeu Edicions 62 (1972, p. 52). 
per tant, es va relacionar la seva obra amb la de la seva muller ${ }^{6}$, que havia guanyat el Premi Ciutat de Mallorca amb la novel·la promocionada. El mateix any es va publicar el text de Joan Triadú titulat "Una generació amb novel·la" (1972), en què descrivia el panorama de la novel·lística catalana, comparant quatre escriptors joves que acabaven de debutar (Llorenç Capellà, Gabriel Janer Manila, Maria-Antònia Oliver i Jaume Fuster) amb les actituds de renovació de novel·listes més coneguts, com ara Capmany o Pedrolo. La ressenya de De mica en mica s'omple la pica de Triadú es va inscriure en la tendència de la bona acollida crítica ${ }^{7}$. A partir d'aquest moment, Fuster va participar activament en el desenvolupament de Serra d'Or. Només en els anys 1973 i 1974 va publicar-hi sis textos, en concret entrevistes que tractaven diferents temes relacionats amb la cultura dels Països Catalans ${ }^{8}$. Per tant, sembla que, com ja suggeria Aritzeta (2014, p. 163), De mica en mica s'omple la pica va ser un factor inqüestionable en el seu procés de consagració com a escriptor i agent actiu en la posició central del sistema.

Aquí també cal recalcar la relació entre la tradició del gènere negre i policíac en castellà $i$ català, atès que les primeres obres van publicar-se en totes dues llengües quasi simultàniament, $\mathrm{i}$ ràpidament van entaular una xarxa de mútues referències. A pesar de la coincidència a l'hora d'iniciar i recuperar aquest gènere en els respectius sistemes, és important reconèixer que els circuits literaris castellà i català presentaven diverses discrepàncies no només a nivell estructural, sinó també conceptual, és a dir, la narrativa dels autors més destacats del panorama literari d'aquell moment s'incloïen dins d'alguns projectes culturals o ideològics $i$, en conseqüència, pretenien acomplir diferents objectius, que, de vegades, eren competitius o semblaven mútuament excloents ${ }^{9}$. Es tracta de dos grups d'escriptors nascuts o establerts als Països Catalans, que van optar per la creació en un dels dos idiomes dominants en el mateix territori. Clarament, la decisió relativa a la llengua d'expressió literària depèn de diferents condicionants, com ara el domini lingüístic desigual per part de la persona o la inclinació cap a un idioma concret per la política estatal de minorització d'un dels idiomes. Com afirma King (2013, p. 32), “[c] on el retorno de la democracia, hubo un

\footnotetext{
${ }^{6}$ Els escriptors es van casar l'any 1969.

${ }^{7}$ Algunes mostres d'aquestes ressenyes són: "Impulso satírico de Jaume Fuster” (Dolç, 1973, p. 47), “De mica en mica s'omple la pica de Jaume Fuster" (J. V., 1972, p. 38), "Una novela de «lladres i serenos»”" (Vilumara, 1972, p. 45). D’altres es poden trobar a Martín Escribà (2018).

${ }^{8}$ Els textos publicats per Fuster són "Rudolf Sirera, un nou teatre a València" (1973c), "Palau i Fabre, el darrer dels alquimistes” (1973b), “«Nino» Buscató, una fidelitat esportiva” (1973a), “Cinc-cents anys després” (1974b), “Josep M. Llompart, les illes recordades” (1974c) i “Catalans a 1'Annapurna” (1974a).

${ }^{9}$ En una entrevista amb Patricia Hart (1987, p. 78-79), el mateix Fuster es queixava sobre la posició minoritzada de la llengua catalana en aquella època i criticava la realitat editorial a Barcelona, que era el centre del món editorial castellà.
} 
deseo por parte de la sociedad catalana de superar la crisis cultural que habían venido sufriendo los catalanes"10.

Tornant al tema d'aquest treball, l'any 1972 va suposar l'inici de la consolidació de la narrativa negra i policíaca per a ambdós sistemes: la publicació de De mica en mica s'omple la pica va coincidir amb l'aparició del detectiu Pepe Carvalho, creat per Manuel Vázquez Montalbán ${ }^{11}$. No obstant això, Yo maté a Kennedy no formava part del cicle de novel la negra d'aquest autor i va constituir més aviat una presentació del personatge que tornaria a aparèixer en futures entregues, fins a l'any 2004. Segons diversos crítics, l'autèntic inici de la crònica de denúncia social de Vázquez Montalbán es troba en la seva segona novel·la de la sèrie, és a dir, Tatuaje (1974). És de cabdal importància fer palès que tant De mica en mica s'omple la pica com Tatuaje inclouen la descripció d'un viatge a l'estranger emprès pels protagonistes que resulta un dels punts més rellevants de l'eix narratiu. L'Enric Vidal, un detectiu amateur de Fuster, decideix acceptar una feina que li ofereix l'amant de la seva germana, en Rodergues, que, a primera vista, sembla només un viatge en cotxe per diferents ciutats europees. No obstant això, al llarg de la narració, ens adonem que no es tracta de viatjar com a representant d'una empresa metal-lúrgica, sinó com a intermediari en el procés de blanqueig de capitals. Mentrestant, el detectiu de Vázquez Montalbán investiga l'enigmàtica mort d'un jove, tant a la Barcelona del tardofranquisme com a Amsterdam i La Haia, on el portaran les pistes recollides sobre el cas. La incorporació d'un viatge a la narració podria vincular-se amb l'imminent acabament de la dictadura franquista i l'arribada de la democràcia, fets que obrien noves perspectives per a tota la societat. Els autors van coincidir en algunes ocasions més i subratllaven que els dos sistemes literaris mantenien contactes fructífers, complementant-se ${ }^{12}$. A més, Vázquez Montalbán va ser una de les nombroses personalitats que van decidir publicar un epitafi literari en homenatge al llegat de Fuster arran de la seva prematura mort

10 A part de l'estudi esmentat en el present article, a l'hora d'entendre la complexitat del fet d'escriure en castellà als Països Catalans resulten interessants les anàlisis d'Estruch Tobilla (1994) o de Saval (2006).

11 El mateix Fuster afirmava que en els anys setanta "hay dos precursores de la novela negra en España, que somos Manolo Vázquez y yo" (Hart, 1987, p. 81). A més, diversos estudiosos han observat aquesta confluència (Martín Escribà, 2006, 2018, o Bennasar, 2011); no obstant això, encara no s'ha analitzat amb profunditat.

${ }^{12}$ Tant Fuster com Vázquez Montalbán van col·laborar en el procés de creació de guions basats en les seves respectives obres. Caldria afegir que es tractava de pel·lícules o sèries de televisió sense massa èxit de crítica ni de públic. Durant els anys 80 van dedicar-se a tasques editorials: de forma anònima, Fuster va proposar novel·les dignes de ser publicades a Seleccions de La Cua de Palla (1985-1996), i des de l'any 1986 va actuar com a assessor (i més endavant director) de la col·lecció La Negra (1975) de La Magrana; mentrestant, Vázquez Montalbán va dirigir Gimlet, revista policiaca y de misterio (1981), que va publicar només 14 números, però comptava amb el suport d'autors i crítics com ara Xavier Coma, Nèstor Luján, Salvador Vázquez de Parga o Eduardo Mendoza. Així mateix, els escriptors van participar en un dels volums de Diàlegs a Barcelona (1985), en què reflexionaven sobre la tradició del gènere negre i policíac a l'Estat espanyol i tota la problemàtica que se'n desprenia. 
l'any $1998^{13}$. Ambdós escriptors van donar nom també a premis ${ }^{14}$, cosa que subratlla la seva aportació indiscutible a la consolidació del gènere negre i policíac a l'Estat espanyol i les respectives posicions centrals d'autors canonitzats.

Tornant a la cronologia de la consolidació de l'obra de Fuster, l'escriptor va rebre el primer premi literari per la seva tercera novel·la, Tarda, sessió contínua, 3.45 (1976), que va reforçar la seva aportació com a escriptor del gènere, però De mica en mica s'omple la pica seguia en potència, i com destaca Aritzeta, "a partir de 1975, quan apareix l'edició de butxaca, es converteix en lectura recurrent dels instituts de secundària durant molts anys" $(2014$, p. 162). És veritat que la venda de certs títols està condicionada per la seva integració en les institucions educatives ${ }^{15}$; un altre exemple d'aquest fenomen és Mecanoscrit del segon origen (1974) de Manuel de Pedrolo. No obstant això, les afirmacions que expliquen el reconeixement d'aquestes obres només mitjançant la seva inclusió en el circuit educatiu semblem simplistes $i$ injustes, perquè desacrediten el valor altament literari dels textos esmentats. El procés d'integració i la consegüent circulació dels textos en el sistema educatiu és complex i, a més, forma part del control de la cultura perquè també entra en el conjunt d'agents a què es referia Even-Zohar (1990, p. 37-38) com a institució. Per tant, a l'hora de preservar un repertori i difondre'l tant com ho havien fet els mitjans de comunicació i les editorials, és important fer-ho a través de la literatura de gènere, que ens pot apropar a l'objectiu coetani de la "normalització" lingüística. Aquesta tendència seguia en potència i, tal com asseverava Bennasar (2011, p. 20), encara "en les anys noranta no era gens difícil trobar títols de novel la negra a les aules del BUP i COU". No obstant això, com explica a continuació, la mateixa dècada va suposar un període de decadència per al gènere negre i policíac, que va iniciar "la desaparició d'aquestes lectures de les aules i la seva substitució pels productes generats per la indústria de la pseudoliteratura juvenil, quasi sempre d'una qualitat literària molt inferior" (Bennasar, 2011, p. 20).

${ }^{13}$ La llista de persones que van decidir dedicar-li un text de comiat és extensa; un exemple d'aquest homenatge pòstum és la sèrie d'articles a Serra d'Or de Llorca, Aritzeta, Graells o Munné-Jordà publicats el mateix any 1998, tots ells referenciats a la bibliografia final. D'altres es poden trobar a Martín Escribà (2018, p. 44-46).

${ }^{14}$ En el cas de Vázquez Montalbán es tracta de dos premis: Premi Internacional de Periodisme Manuel Vázquez Montalbán, atorgat des de l'any 2004 en dues categories (Periodisme Cultural i Polític i Periodisme Esportiu) i Premi Pepe Carvalho, concedit des de l'any 2006 a autors de qualsevol nacionalitat com a reconeixement de la seva aportació al camp de la novel·la negra i policíaca mundial. El Premi Jaume Fuster dels Escriptors en Llengua Catalana va començar a atorgar-se l'any 2001. Un altre tipus d'homenatge són les biblioteques que duen el nom dels autors, a Barcelona (Fuster, 2005) i Madrid (Vázquez Montalbán, 2006).

${ }^{15}$ El mateix Fuster reconeixia la importància de la integració de De mica en mica s'omple la pica en el sistema educatiu: "La cosa comença [...] quan fou recomanada als infants de les escoles, perquè es considerava de lectura senzilla. I ves per on, ara ja se n'han venut cent vint mil exemplars, només en la versió catalana. S'ha traduït a diversos idiomes i, fins i tot, se n'ha fet un guió per a una pel-lícula i és possible que un guió per a televisió" (Riera, 1986, p. 56-57). 


\section{JAUME FUSTER I EL SEU INTENT DE CONSOLIDAR EL GĖNERE A CATALUNYA}

Fuster era conscient de la importància del seu projecte literari perquè justament l'any 1972 va escriure un curt article titulat "Ja sou lectors de novel·les de lladres i serenos?". És un text que problematitzava el fracàs editorial d'aquest tipus de literatura i presentava dues propostes de canvi. Per a Fuster, el problema consistia en la manca de protagonistes creïbles i la mania de transcendentalisme en la narrativa catalana de l'època, i les recomanacions que donava es derivaven de les opcions triades a $D e$ mica en mica s'omple la pica. De fet, va posar-la com un bon exemple de narració des de la perspectiva d'un delinqüent (entre És hora de plegar de Tasis i Joc brut de Pedrolo) i sembla que amb aquest article ho va deixar molt clar: acabava de publicar una novel-la de lladres de serenos de qualitat i preguntava tot murri als lectors si ja estaven preparats per poder gaudir-la.

La novel la de Fuster mostra una multitud extraordinària de referències intertextuals pròpies del gènere negre i policíac. Genette (1989) defineix aquestes relacions genèriques com l'arxitextualitat, una funció que emparenta textos pertanyents al mateix gènere literari. Per tant, els autors que opten per escriure una novel la negra o policíaca haurien de tenir en compte els elements constitutius d'aquest arxigènere narratiu i emprar-los en les seves narracions per guiar adequadament l'horitzó d'expectatives dels lectors. De mica en mica s'omple la pica també ho fa, però s'adapta a la singular situació del gènere negre i policíac a Catalunya, és a dir, Fuster modifica aquests components perquè siguin més creïbles per als lectors no familiaritzats amb el gènere, $i$ els orienta a través del text, afegint pistes que els ajudaran a ubicar-se millor en la geografia d'aquest tipus de narrativa.

La part introductòria, que en aquest cas també exerceix una funció didàctica, es compon d'uns elements que no formen part de la narració, és a dir, el títol de la novel·la, les dedicatòries, la llista de personatges i vuit notes i reculls de citacions. Tot plegat cal analitzar-ho en el context de l'intent d'introduir el gènere al sistema literari català. D'aquesta manera, tant el títol com el fragment procedent del muntatge $\mathrm{Ba}$ lades del clam i la fam $^{16}$ de Xavier Fàbregas i Josep A. Codina planteja la complexa problemàtica d'un desenvolupament més aviat massa lent de la tradició catalana que, amb la publicació d'aquesta novel·la, finalment aconseguia cert èxit. Les dedicatòries esbossen un panorama de les relacions familiars i professionals o literàries entre diferents sistemes. Les categories d'aquests vincles són difuses i sovint es barregen entre elles, però hi destaquen agraïments per als escriptors i traductors catalans de l'equip de La Cua de Palla, cosa que demostra la importància de la traducció com a eina d'im-

\footnotetext{
${ }^{16}$ Es tracta d'una obra estrenada a la Cúpula del Coliseum de Barcelona l'any 1967. Se sabia que Fuster coneixia l'obra perquè assistia a un curset de teatre de la Universitat Catalana amb Xavier Fàbregas de professor, entre d'altres, i com a obra de final de curs l'alumnat va muntar una peça que pertanyia a Les balades del clam i la fam sota la direcció de F. Nel·lo (Redacció, 1972, p. 1042).
} 
plementació un cert model argumental en qualsevol sistema ${ }^{17}$. A més a més, a partir d'aquestes dedicatòries es pot concloure que Fuster volia que la seva obra encaixés en un nou model socioinstitucional que, si bé s'iniciava seguint les pautes i l'estil de la col·lecció, tenia com a objectiu bastir una nova orientació global de la literatura catalana sota el paradigma de la "normalització". La resta dels agraïments podien servir com una xarxa de referències literàries que van ser font d'inspiració per a Fuster, no solament en la seva etapa de formació com a lector, sinó també com a escriptor del gènere. Els detectius esmentats mostren influències procedents d'altres sistemes literaris, atès que es poden dividir en dos grups en funció de la nacionalitat dels seus autors, anglosaxons i francòfons, amb preponderància dels primers ${ }^{18}$. Un altre criteri que es pot emprar a l'hora de dividir-los és la terminologia aplicada a l'hora de cata$\operatorname{logar}-\operatorname{los}^{19}$. Val a dir també que quatre dels vuit autors esmentats a les dedicatòries van ser publicats a La Cua de Palla ${ }^{20}$. Finalment, l'últim element que forma part d'aquesta novel·la sense ser-ne eix narratiu són les notes i citacions, les quals, d'alguna manera, poden vincular-se amb la necessitat i l'oportunitat de Fuster per explicar per a què serveix el gènere negre i policíac en el panorama literari català. Els autors citats representen un grup heterogeni, en el sentit que procedeixen tant de l'àmbit literari com del teòric. D'aquesta manera, a fi de reflexionar sobre la legalitat i el delicte en la narrativa policíaca, Fuster feia referència a Salvador Giner, un destacat sociòleg català, i per indicar com es relaciona la novel-la negra amb la política, utilitzava fragments de les obres de Hammett, Spillane i Hadley Chase. Aquí també s'observa la influència dels sistemes forans perquè els dos primers autors apareixien a les dedicatòries i els textos

${ }^{17}$ Com ja hem comentat breument, les traduccions van exercir una funció rellevant en el procés d'implementar el gènere negre i policíac en els sistemes literaris on encara no s'havia desenvolupat. En aquest sentit, King (2014, p. 9-10) advertia que els investigadors de països no anglosaxons les consideraven sovint una etapa necessària per al desenvolupament del gènere nacional. $\mathrm{A}$ fi de reflexionar sobre el procés de creació dels fonaments de la tradició catalana, King (2017, p. 159-160) evoca el terme "anostrar" i el plantejament teòric dels polisistemes d'Even-Zohar.

${ }^{18}$ Els detectius que formaven part de la tradició anglosaxona són els següents: Sherlock Holmes d'Arthur Conan Doyle, Sam Spade i Nick Charles de Dashiell Hammett, Philip Marlowe de Raymond Chandler, Mike Hammer de Mickey Spillane, Perry Manson d'Erle Stanley Gardner i Charles Auguste Dupin d'Edgar Allan Poe. El comissari Maigret de Georges Simenon i Arsène Lupin de Maurice Leblanc provenen de la tradició francòfona.

${ }^{19}$ En aquest sentit, hi ha més autors que publicaven les seves obres seguint el model de la novel·la hardboiled nord-americana (Hammett, Chandler, Spillane). La resta dels autors encaixa més aviat en l'àmbit de la novel·la policíaca clàssica.

${ }^{20}$ Les novel·les de Hammett eren The Glass Key $(1931,1963)$, The Maltese Falcon $(1950,1966)$, The Thin Man $(1934,1967)$ i Red Harvest $(1929,1968)$; de Simenon, La tête d'un homme $(1933,1964)$, L'homme qui regardait passer les trains (1938, 1964), Le pendu de Saint-Pholien (1931, 1964), Liberty Bar (1932, 1965), Le charretier de la Providence (1931, 1965), La nuit du carrefour (1931, 1966), Le chien jaune (1931, 1967), L'homme de Londres (1934, 1967), L'ombre chinoise (1932, 1967), Maigret et le client du samedi $(1962,1968)$, Signé Picpus $(1941,1968)$ i Le Relais d'Alsace $(1931,1970)$; d'Spillane, The Depp $(1961,1964)$; i de Chandler, The Lady in the Lake $(1963,1966)$ i The Big Sleep $(1939,1966)$. 
esmentats van ser publicats a La Cua de Palla l'any 1968, aparentment mentre Fuster estava en ple procés d'escriptura de De mica en mica s'omple la pica ${ }^{21}$.

L'argument d'aquesta novel·la gira entorn de la figura de l'Enric Vidal, que, com ja hem comentat anteriorment, accepta una feina que li proposa el Rodergues, l'amant de la seva germana. Des de l'inici, sospita que aquest encàrrec suposa un negoci il·lícit, però es compromet a realitzar la tasca amb un sou més elevat. Desgraciadament, quan torna a Barcelona, troba els cadàvers d'en Rodergues i la Júlia. Aquest descobriment fa que Vidal decideixi iniciar pel seu compte la investigació per trobar el culpable i aclarir els motius que l'han dut a cometre els crims. Per tant, no es tracta d'un detectiu professional, sinó més aviat d'un investigador amateur forçat per les circumstàncies a esbrinar la veritat oculta, perquè sap que les autoritats policials oficials solen aliar-se amb les castes importants i adinerades de la societat i ell no encaixa amb aquest perfil. Sembla que Vidal posseeix algunes característiques pròpies de l'arquetipus del detectiu, encara que no siguin destreses ben desenvolupades. El nostre investigador molt sovint confia en la seva intuïció, com ho fa després de trobar el cadàver d'en Rodergues:

Vaig recollir les llosques dels dos cigarrets que m'havia fumat allí dedins, vaig ben escampar la cendra, i, amb el mocador, vaig netejar els muntants de la porta i els interruptors. No sabia ben bé per què ho feia, però alguna cosa dintre meu em deia que calia fer-ho. Després vaig sortir, ajustant la porta, tal com l'havia trobada ${ }^{22}$. (p. 64)

Fa el mateix en l'escena del crim de la Júlia, però, com que és la seva germana, decideix cobrir el seu cadàver:

La Júlia només duia una camisa de dormir que se li arregussava més amunt de les natges, descobrint impúdicament la seva pell, ratllada per la franja del banyador. Instintivament vaig cobrir-li les cuixes. (p. 87)

A més, Vidal és capaç de treure conclusions encertades i anticipar activitats que duran a terme tant les autoritats policials com els "peixos grossos" i els seus pinxos. Sabem només allò que ell mateix desitja contar-nos, però aquesta informació és suficient per adonar-nos que es tracta d'un home marcat per les experiències de la vida. Com que és el representant d'un grup generacional concret (mai no ha pogut acabat la carrera, se n'ha anat a l'Àfrica per fer el servei militar, etc.), és possible que també hagi rebut la mateixa autoformació de l'època en què dominaven les pel·lícules nord-americanes, les novel·les de gènere o els tebeos. Les seves habilitats poden relacionar-se amb alguns models d'actuació en cert tipus de situacions, com ara les

${ }^{21}$ Es tracta dels números 61 i 63 de La Cua de Palla, és a dir, The Guilty Are Afraid (1957) de Hadley Chase i Red Harvest (1929) de Hammett.

${ }^{22}$ Les citacions indiquen la pàgina de la reedició de la novel·la de 2016, referenciada a la bibliografia final. 
persecucions policials, però, al mateix temps, semblen operacions bastant lògiques, per exemple l'escena a l'hotel al qual torna després d'haver vist el cadàver de la seva germana: "El primer lloc on mirarien, si em buscaven, seria a les dispeses. I els hotels lliuren una fitxa de cadascun dels viatgers a la comissaria" (p. 93).

Com ja s'ha anat subratllant, el repertori dels personatges encaixa plenament amb els models tòpics del gènere, és a dir, tenim representants de cada grup econòmic, necessaris per poder plantejar el problema de les injustícies socials. En la majoria de la narració, els "peixos grossos" i els seus "assistents" són els dolents de la història, però les fronteres desapareixen entre allò que es considera que està bé i malament, cosa que reflecteix la realitat $i$ atorga al text cert grau de versemblança. D'aquesta manera, els lectors no solament poden identificar-se amb la història, sinó també entendre millor la psique dels protagonistes: Júlia Vidal és prostituta, però el seu ofici es pot explicar com l'única manera de guanyar diners, mentre que Enric Vidal és cínic, dur $i$ agressiu, com a resultat de les experiències viscudes: sap que només així pot vèncer els obstacles. Encara que els personatges duguin noms i cognoms concrets, més aviat representen col-lectius recognoscibles fàcilment pels lectors. Com diu Martín Escribà (2018, p. 97), la modificació dels elements argumentals emprada per Fuster s'observa també en la representació dels personatges femenins. A vegades, s'aplica un enfocament compatible amb el gènere, que és preservat per la cinematografia nord-americana dels anys 40 i 50, presentant-les des de la seva timidesa en contacte amb els homes o subratllant-ne l'aspecte carnal. Un dels exemples d'això és la descripció de les secretàries d'una oficina on Vidal observa les cames d'una d'elles, esperant la cita amb en Rodergues:

hi havia dues mosses que tecletejaven amb desesma unes velles Underwood i que, després de llançar-me tímides mirades de tant en tant, feien petar la xerrada, un zumzeig inaudible per a mi. (p. 67)

Aquesta imatge contrasta amb les dones que treballen al Billy's:

[e]ra una noia rossa, rossa, d'ulls encerclats de negre, que sostenia el cigarret amb gest d'actriu de cinema. Quan petà l'encenedor, la mitjameuca s'ajupí una mica, deixant que l'escot rodó del vestit mostrés el pitam. (p. 154)

Un dels personatges creibles és la senyora Núria que, segons el narrador, és una portera "xafardera, rondinaire, maternal i típicament barcelonina" (p. 55). Tradicionalment, si apareix a la narració aquest personatge arquetipus, es tracta d'una persona que observa silenciosament tot allò que succeeix en un edifici. Aquí el canvi es relaciona amb una figura més propera als lectors que, al mateix temps, transmet en els seus comentaris molta informació sobre la mentalitat d'una part de la societat. En principi, la senyora Núria no permet cohabitar amb dones al seu edifici i té prejudicis 
contra els estrangers. Al final, accepta la parella del Vidal, però només perquè li ha dit que són casats. De fet, aquest personatge femení es pot analitzar des de dos nivells de lectura diferents. D'una banda, el text exposa i ridiculitza la realitat que l'envolta, cosa que significa la introducció d'un component humorístic essencial per al gènere negre i policíac: sembla que la portera controla detalladament els inquilins de l'edifici, per bé que no és capaç de fer-ho en la seva vida conjugal; ho sabem perquè va contar al Vidal "una història complicadíssima del seu marit i una alemanya" (p. 99). A més, el seu procés deductiu no és gaire lògic, perquè assumeix que tots els estrangers causen dificultats, plasmant-ne així una imatge errònia i nociva, reproduïda habitualment en el discurs públic del règim franquista. En conseqüència, la seva aversió xenòfoba encarna els models típics de l'època, i el públic lector és capaç de descodificar aquesta imatge i associar-la amb l'omnipresent propaganda dictatorial. Tot i que la portera sembli plantejar unes conclusions extretes de les seves vivències, ens adonem que els prejudicis cristal-litzats en aquest personatge reflecteixen els components ideològics que formaven part del repertori divulgat pel franquisme i emprat per a l'adoctrinament de la societat coetània.

Aquestes idees contrasten amb la figura d'una jove turista belga ${ }^{23}$, Bebel Dupin, i tal com afirma Aritzeta (2014, p. 170), "amb Jaume Fuster cap coincidència de nom no és casualitat". El cognom d'aquest personatge coincideix amb Auguste Dupin, el detectiu d'Edgar Allan Poe, però, al mateix temps, subratlla l'aportació de l'obra de Simenon tant reconeguda a Catalunya, que era de Bèlgica. Els homenatges literaris o cinematogràfics constitueixen una de les característiques més importants de l'obra de Fuster i, segons Aritzeta (2014, p. 168), "lliguen la literatura catalana amb les altres literatures $\mathrm{i}$ aporten al lector català la familiaritat d'uns personatges, uns autors i unes obres que són patrimoni del món". Sembla que la Bebel té tres funcions diferents al llarg de la novel·la: és parella del personatge principal, amb qui manté una relació típica del gènere, l'acompanya en la investigació i encarna el mite de "l'Europa alliberada enfront del darrer franquisme" (Martín Escribà, 2018, p. 53). El més interessant és, sens dubte, el segon punt, perquè en aquell moment les dones no podien convertir-se en detectius "legítims"24. La Bebel intenta ajudar el Vidal i el guia en la seva investigació. De vegades, aquest suport significa que l'Enric parli amb algú i expressi en veu alta els pensaments que li distorsionen la percepció del món. Aquest procediment pot ser una influència de l'obra de Dashiell Hammett, esmentat a les

${ }^{23}$ Martín Escribà (2018, p. 97) assenyala que "la narrativa dels setanta es va fer ressò de la reivindicació dels drets igualitaris de les dones" $i$, per tant, reconeixia que la configuració del personatge d'Isabelle Dupin també hauria d'analitzar-se en aquest context, com "l'estereotip de dona moderna europea" de la mateixa època.

${ }^{24}$ Maria Antònia Oliver va ser la primera autora en el panorama literari català que va incorporar un personatge femení com a detectiu principal. Lònia Guiu va aparèixer en les novel·les Estudis en lila (1985), Antípodes (1988) i El sol que fa l'ànec (1994). 
dedicatòries, atès que és allí on Fuster reconeix que Nick Charles, un dels personatges de l'autor nord-americà, l'ha impressionat fortament. Charles apareix a la novel'la The Thin Man (1934, L'home flac [1967]), on resol amb la seva muller, la Nora, uns casos de morts enigmàtiques.

\section{CONCLUSIONS}

En resum, De mica en mica s'omple la pica adopta una posició ambigua en la cronologia del desenvolupament del gènere negre i policíac a Catalunya, perquè, d'una banda, no nega l'aportació anterior de Tasis ni de Pedrolo i continua amb el compromís ideològic de normalitzar la llengua i la cultura catalanes, però, de l'altra, se situa en oposició als models tradicionals, modificant-los i actualitzant-los per a un públic lector concret que, simultàniament, s'intenta crear. D'aquesta manera, Fuster duu a terme un complex procés d'integració dels elements referencials d'una modalitat genèrica concreta en un discurs totalment diferent, que també està condicionat pels moments històrics pertanyents a la dimensió local específica i, al mateix temps, forma el repertori col·lectiu de tot un grup generacional del qual el mateix escriptor és el màxim representant. Fuster introdueix un pacte literari amb els seus lectors que, coneixent les regles del gènere negre i policíac dels sistemes forans i dominants a través de produccions anteriors de la cultura popular en diferents mitjans d'expressió artística, són capaços d'ubicar-se en el nou context de la novel·la negra i policíaca en llengua catalana, enriquida amb el reflex mimètic de l'època i un vast ventall de referències culturals i literàries pròpies d'aquest gènere. Sembla que aquesta novel la no solament consolida el gènere, sinó que també presenta un conjunt de tècniques subversives tant en el pla narratiu com en l'inventari temàtic. Gràcies al projecte literari de Fuster, la ficció policíaca en català assoleix una de les seves característiques més significatives: la versemblança, que es manifesta a nivell lingüístic i en la configuració d'uns personatges creïbles, amb unes motivacions inspirades en les condicions de vida de l'època en què s'estan formant els lectors potencials d'aquest tipus de literatura. A més, l'obra de Fuster coincideix amb uns canvis geopolítics favorables i amb la reorganització de l'estructura del sistema literari i els seus agents. Així doncs, les novel-les negres i policíaques poden coexistir amb altres textos del repertori literari, entrant-hi en diàleg o fins i tot rivalitzant per les posicions centrals d'aquest sistema. La renovació de referències ideològiques i literàries influeix en la construcció d'un autèntic circuit on els autors i les autores d'un grup generacional concret, al qual pertany també Fuster, exerceixen funcions diferents, però compatibles amb la idea global de legitimació -i l'eventual canonització consegüent- de la nova producció literària en llengua catalana. El mateix Fuster esdevé una de les persones que contribueix al sorgiment de la nova infraestructura editorial, posant les bases d'una plataforma efi- 
caç que pugui difondre certs models narratius $i$, en conseqüència, els popularitzi amb la finalitat de garantir un ampli moviment d'influències (de vegades mútues) entre diferents tradicions literàries.

A pesar del caràcter minoritzat del sistema literari català, l'intent d'implementació i la següent consolidació de la narrativa negra i policíaca per part de Fuster no es diferencia significativament d'altres processos observats al llarg del desenvolupament de la tradició mundial d'aquest gènere, és a dir, les primeres publicacions quasi sempre suposaven unes veus subversives i marginals que, en principi, s'oposaven als gèneres que tradicionalment ocupaven les posicions centrals del sistema literari d'una societat concreta. En aquest sentit, destaca també la importància de tots els membres de la institució, la qual, amb les seves eines, facilita la incorporació de certs tipus de textos, amb la consegüent promoció d'autors que, en ocasions, atenyen la consagració. A més, les referències intertextuals procedents d'altres sistemes que contribueixen a crear una base sòlida per a les produccions locals no resulten de fet una anomalia, atès que en el gènere policíac universal podem observar una circulació de continguts similar. Finalment, en la singularitat de l'obra de Fuster rau un canvi de sentit destacable quant a la dinàmica entre els sistemes juxtaposats a l'Estat espanyol, perquè la transferència es duu a terme també des del sistema perifèric al sistema dominant, en aquest cas el castellà. 


\section{REFERÈNCIES BIBLIOGRÀFIQUES}

Arbonès i Montull, J. (2018). Pedrolo contra els límits. Lleida: Pagès Editors. Aritzeta, M. (1998). El compromís amb la literatura. Serra d'Or, 461, 14-18. Aritzeta, M. (2014). Jaume Fuster, la ficció sense fronteres. Ítaca, 5, 161-177.

Bennasar, S. (2011). Pot semblar un accident. La novel·la negra i la transformació dels Països Catalans 1999-2010. Barcelona: Meteora.

Canal Artigas, J. \& Martín Escribà, À. (2011). La cua de palla: retrat en groc i negre. Barcelona: Alrevés.

Dolç, M. (1973, 6 de setembre). Impulso satírico de Jaume Fuster. La Vanguardia, p. 47.

Edicions 62 (1972). La col·lecció de novel·les El Balancí. Serra d’Or, 153, p. 52.

Estruch Tobilla, J. (1994). El català en la narrativa castellana escrita a Catalunya. Els casos de Mendoza, Marsé i Vázquez Montalbán. Catalan Review, 8 (1-2), 153-160.

Even-Zohar, I. (1990). Polisystem Studies. Poetics Today, 11 (1).

Febrés, X. (trans.) (1985). Diàlegs a Barcelona: Manuel Vázquez Montalbán i Jaume Fuster. Barcelona: Laia.

Fuster, J. (1972). Ja sou lectors de novel·les de lladres i serenos? Dins À. Martín Escribà, Jaume Fuster, gènere negre sense límits (p. 141-142). Barcelona: Alrevés.

Fuster, J. (1973a). "Nino" Buscató, una fidelitat esportiva. Serra d'Or, 171, desembre, 41-45.

Fuster, J. (1973b). Palau i Fabre, el darrer dels alquimistes. Serra d'Or, 164, maig, 17-20.

Fuster, J. (1973c). Rodolf Sirera, un nou teatre a València. Serra d'Or, 161, febrer, 53-54.

Fuster, J. (1974a). Catalans a l'Annapurna. Serra d'Or, 180, setembre, 15-19.

Fuster, J. (1974b). Cinc-cents anys després. Serra d'Or, 181, octubre, 31-34.

Fuster, J. (1974c). Josep M. Llompart, les illes recordades. Serra d'Or, 176, maig, 29-32.

Fuster, J. (2016). De mica en mica s'omple la pica. Barcelona: Edicions 62.

Genette, G. (1989). Palimpsestos. La literatura en segundo grado (trad. de C. Fernández Prieto). Madrid: Taurus.

Graells, G.-J. (1998). Narrador i prestigitador. Serra d'Or, 461, 19-21.

Hart, P. (1987). Spanish Sleuth. The Detective in Spanish Fiction. Rutherford: Fairleig Dickinson University Press.

J. V. (1972, 27 de juliol). "De mica en mica s'omple la pica", de Jaume Fuster. La Vanguardia, p. 38.

King, S. (2013). Carvalho y Cataluña: la subjetividad de los márgenes. MVM: Cuadernos de Estudios Manuel Vázquez Montalbán, 1, 28-45.

King, S. (2014). Crime Fiction as World Literature. Clues, 32 (2), 8-19.

King, S. (2017). Making it Ours. Dins L. Nilsson, S. Samrosch \& T. D’haen (eds.), Crime Fiction as World Literature (p. 157-169). Nova Delhi: Bloomsbury.

Llorca, V. (1998). Petit retrat de Jaume Fuster. Serra d'Or, 461, 12-13.

Martín Escribà, À. (2006). Una autòpsia a la literatura de lladres i serenos. Estudios Catalanes, 4, 149-159.

Martín Escribà, À. (2015). Rafael Tasis, novel lista policíac. Barcelona: Alrevés.

Martín Escribà, À. (2018). Jaume Fuster, gènere negre sense limits. Barcelona: Alrevés.

Martín Escribà, À. (2020). Escrits policíacs, de "La Cua de Pall" a "Crims.cat". Barcelona: Alrevés.

Munné-Jordà, A. (1998). L'altra literatura de Jaume Fuster. Serra d'Or, 461, 22-24.

Pagès, R. (2013). Jaume Fuster i l'ofici d'escriure. Congrés La Generació dels 70. Recuperat de http:// delllibrealsdits.blogspot.com/2013/10/jaume-fuster-i-lofici-descriure.html.

Pedrolo, M. de (1972). Que falla, la cua de palla? Serra d'Or, 149, febrer, 44-46.

Redacció (1972). Revista del Centre de Lectura de Reus, 226, agost, 1042. Recuperat de https://www.raco. cat/index.php/RevistaCLR/article/view/139106.

Riera, M. (1986). Totes les claus de vidre. El Temps, 109, 56-58. 
Saval, J. V. (2006). La particular relació de Manuel Vázquez Montalbán amb la Catalanitat. Revista Internacional de Catalanística (Journal of Catalan Studies), 9, 110-116.

Triadú, J. (1972). Una generació amb novel·la. Serra d’Or, 156, setembre, 43-46.

Vázquez Montalbán, M. (1998, 1 de febrer). L'obra ben feta. Avui, p. 51.

Villalonga, A. M. (2013). Les veus del crim. Barcelona: Alrevés.

Vilumara, M. [pseud. de Josep Batlló] (1972, 14 de setembre). Una novela de "lladres i serenos". La Vanguardia, 45. 